\title{
A STUDY OF GPS POSITIONING ERROR ASSOCIATED WITH TROPOSPHERIC DELAY DURING NUMA MEDITERRANEAN CYCLONE
}

\author{
Ivan Rumora ${ }^{1}$, Oliver Jukić ${ }^{2}$, Mia Filić ${ }^{3}$, Renato Filjar ${ }^{4}$ \\ ${ }^{1}$ Croatian Navy, Pula, Croatia \\ ${ }^{2}$ College for Management in Tourism and Informatics, Virovitica, Croatia \\ ${ }^{3}$ Faculty of Electrical Engineering and Computing, University of Zagreb, Croatia \\ ${ }^{4}$ Faculty of Engineering, University of Rijeka, Croatia
}

Received 17 April 2018; accepted 20 May 2018

\begin{abstract}
The adverse and rapidly changing weather conditions during a Mediterranean cyclone (medicane) pose a serious threat to maritime navigation in general. Additionally, failure in correction for GNSS signal tropospheric delay was supposed to significantly degrade the quality of GNSS-based position estimation. Here we present the study results aimed at determination of GPS positioning performance quality and GPS tropospheric error based on experimental observation during the November 2017 medicane. We found identifiable degradation of GPS positioning performance due to medicane-caused tropospheric delay, and propose corrective actions aimed at maintaining GPS positioning performance resilience for several classes of GNSS maritime applications.
\end{abstract}

Keywords: GPS positioning accuracy, GPS tropospheric delay, maritime navigation, medicane.

\section{Introduction}

Satellite navigation has become a component of national infrastructure and is considered a public good, since it provides an enabling framework for development of numerous technology and socio-economic systems in foundation of the modern civilisation (UN OOSA, 2012), (Thomas et al., 2011). The error budget of the core Global Navigation Satellite System's (GNSS) Positioning, Navigation, and Timing (PNT) services have been established for some time. However, in the application-oriented society, it has become increasingly important to address the impact of the GNSS PNT performance degradation on the quality of the GNSSfounded applications and services.

Weather deterioration is often neglected or overlooked source of the GNSS tropospheric delay, and GNSS positioning performance degradation. Such a treatment of GNSS tropospheric delay may consequently affect the performance of the classes of GNSS applications, particularly those in support of safety-critical applications and services, and precise navigation and mobility.

Here we contribute to assessment of the GNSS positioning performance and GNSS-based applications quality of service

${ }^{2}$ Corresponding author: oliver.jukic@vsmti.hr 
degradation in maritime navigation domain due to weather deterioration, through the study of GNSS positioning performance degradation during the intense cyclone development in the Mediterranean region. Estimated GNSS positioning errors were discussed in relation to requirements of maritime GNSS-based applications to reveal potential risks of utilisation of GNSS observations inappropriately corrected for unusual tropospheric delay dynamics. The results of analysis were used for derivation of recommendations for the GNSS tropospheric delay treatment in maritime navigation applications domain.

\section{GPS Tropospheric Delay Associated with Numa Medicane}

A Mediterranean tropical-like hurricane (cyclone) is a rare meteorological phenomenon that resembles the open ocean hurricanes and cyclones, and, as its name suggests, takes place in Mediterranean region (Tous and Romero, 2013). Records show its occurrence with repetition period ranging decades, but recent studies show increased frequency of the phenomenon also called a medicane (Romero and Emanuel, 2017).

In general, a medicane poses a significant threat to maritime safety, navigation and traffic (Cavicchia et al., 2014). Rapidly deteriorating weather conditions (Nauenberg, 2016), (Markežić et al., 2002), such as those related to medicane development, have a potential to affect GNSS positioning conditions (Shrestha, 2003) by introduction of the unknown contribution to tropospheric delay of a GNSS signal. It is essential that positioning performance of navigation systems, including satellite navigation, remain undisrupted and robust during such events (Thomas et al., 2011). Hence the rationale for an advanced understanding of the medicane effects on GNSS positioning performance.

\subsection{Background Research}

Tropospheric delay of GPS signal is a known contributor to GPS positioning error budget (Cove, 2005). The nature of GPS tropospheric delay is related to satellite signal refraction effects caused by variable index of refraction due to inhomogeneities in the troposphere during weather developments. The GPS tropospheric delay can be defined analytically using Eq. (1):

$d_{\text {tropospheric }}=\int_{\text {along the path }}(n-1) * d s$

where the integral is taken along the satellite signal's path through the troposphere.

Rescaled refraction index $N$, given in Eq. (2) as:

$$
N=10^{-6} *(n-1)
$$

emphasises the variations in refractive index due to weather development.

The refractive index value comprises the effects of both dry and wet air on the radio (satellite) signal propagation. Thus, the over-all tropospheric refractive index may be represented with a dry-air $\left(N_{d r y}\right)$ and wet$\operatorname{air}\left(N_{w e t}\right)$ components, as given in Eq. (3):

$$
N=N_{\text {dry }}+N_{w e t}
$$


Both components contribute to formation of the GPS tropospheric delay, as given in Eq. (4) and derived from Eq. (1) and Eq. (3):

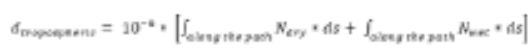

Precision satellite navigation applications have been requiring the mitigation of positioning error sources for decades, usually through deployment of correction models. Tropospheric effects on radio communication systems has been extensively studied in the post-WWII era (Sweezy and Bean, 1962), resulting with a number of tropospheric correction models deployed in satellite navigation today (Katsougiannopoulos et al., 2006). (Hohenkerk and Sinclair, 1985) presented one of the earliest systematic methods for tropospheric delay practical estimation.

The Hopfield correction model Eq. (5) assumed concentration of tropospheric delay in the infinitesimally thin layer of troposphere described with the respective meteorological parameters $\left(T_{s} \ldots\right.$ absolute surface air temperature in $[\mathrm{K}], p_{s} \ldots$ total surface air pressure in $[\mathrm{hPa}], e_{s} \ldots$ partial water vapour pressure in $[\mathrm{hPa}]$ ), at the heights above the sea level of $H_{d e}$, for dry-air component, and $\mathrm{H}_{w e}$, for wet-air component, respectively:

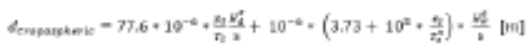

The Saastamoinen correction model Eq. (6) is established on the user-oriented approach, taking into consideration the measurable meteorological parameters in direct user environment ( $T$.. absolute air temperature in $[\mathrm{K}], p \ldots$ total surface air pressure in $[\mathrm{hPa}]$, e... partial water vapour pressure in $[\mathrm{hPa}]$ ), with $z$ as the zenith angle:

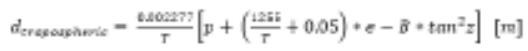

The Saastamoinen model is considered a standard for satellite navigation tropospheric delay correction, and a benchmark for scientific activities in studying tropospheric delay of satellite signals. In the absence of real observations of meteorological parameters, some GPS receivers deploy the utilisation of the standard atmospheric model for calculation of the related values of weather parameters.

Correction model deployment is not the only means for mitigation of the GPS tropospheric delay effects. Modern approaches often involve utilisation of statistical models, information fusion and machine learning methods and techniques (Cove, 2005). One of us (Filić, 2017) demonstrated the advantage of utilisation of Weighted Least Square Method (WLSM) in navigation algorithm for pseudo-range-based position estimation without the requirement for a dedicated correction model.

In common meteorological scenarios, the GPS tropospheric delay can be described using a simple model that ads fast-varying small-amplitude wet-air delay component to prevailing constant large-amplitude dry-air delay component. Tropospheric delay has been considered simply as a bias for majority of navigation applications, including those in maritime segment, rendering the GPS tropospheric delay uncompensated for, and as the potential cause of the GPS positioning performance disruptions, with potential safety and navigation consequences. 


\subsection{Numa Medicane Event Description}

According to meteorological records (Free University of Berlin, 2017), (Royal Netherlands Meteorological Institute, 2018), the most recent medicane case developed in the central Mediterranean region on 14 November, 2017 on the remnants of an Atlantic Ocean anomaly that entered Mediterranean (Fig. 1). The medicane, called Numa by the register maintained by (Free University of Berlin, 2017), caused loss of lives and substantial damage, first in central Mediterranean islands and southern Italy, and then in Greece (16 November, 2017), after which it dissipated on 17th November, 2017. One of the authors (IR) encountered the event directly, while performing his duty in the region affected by medicane.

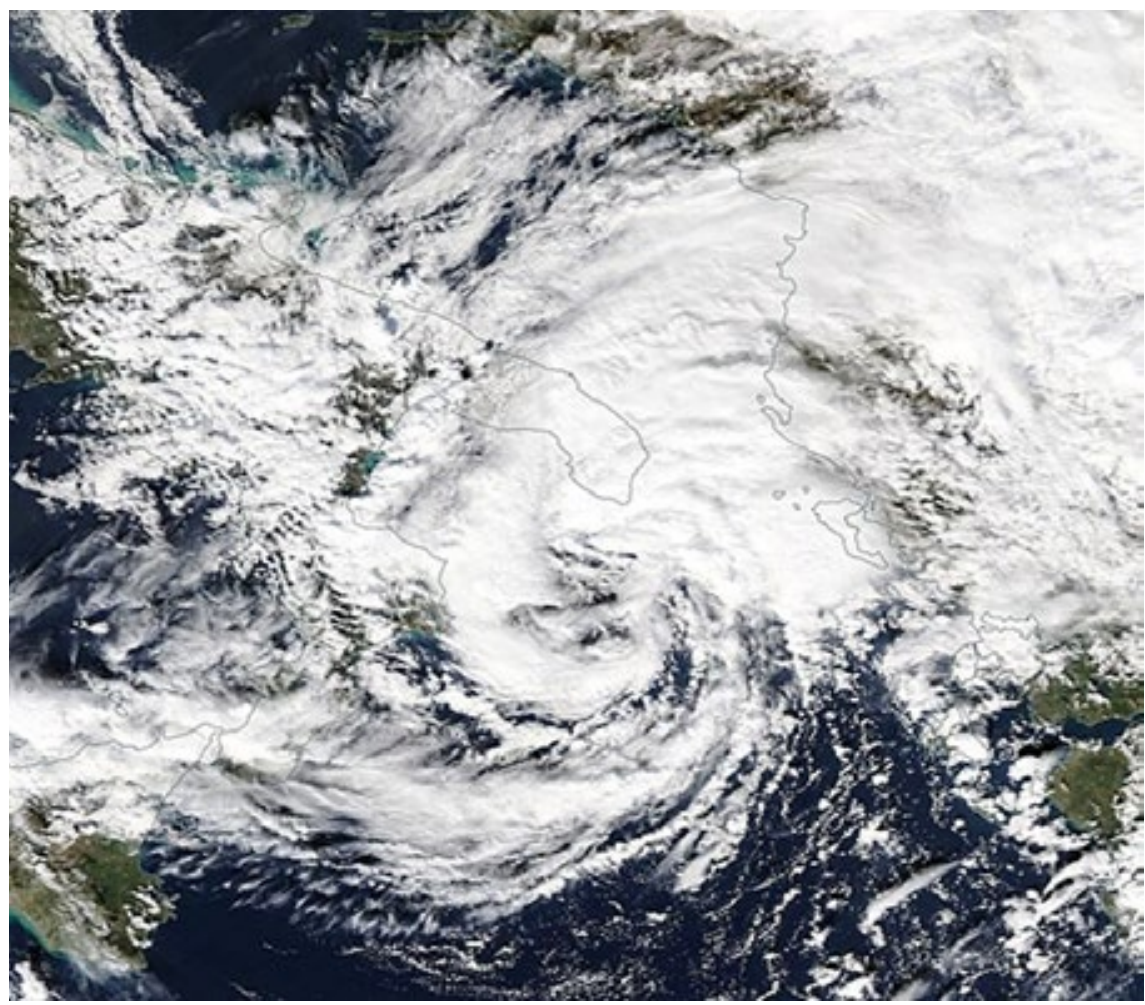

Fig. 1.

Satellite Photography of the Fully-Developed Numa Storm on $15^{\text {th }}$ November, 2017

Source: (NASA, 2017)

A rapid development of the medicane and availability of the related observation records rendered the Numa medicane a valuable case-study for an evaluation of
GPS positioning performance during rapidly changing adverse tropospheric conditions, and the risk assessment of GPS utilisation in maritime navigation. 


\subsection{Research Methodology}

The choice of the simulation-based methodology of GNSS positioning performance study during the 2017 medicane event in southern Italy was motivated with the availability of continuously collected raw GNSS pseudorange observations (24 hours per day, with samples taken every $30 \mathrm{~s}$ ) This study is based on raw GNSS pseudorange data taken at the SONET GNSS reference station at Lampedusa (Fig. 2), and the IGS records of broadcast GPS navigation messages, both stored in the compressed RINEX format and available freely for scientific studies.

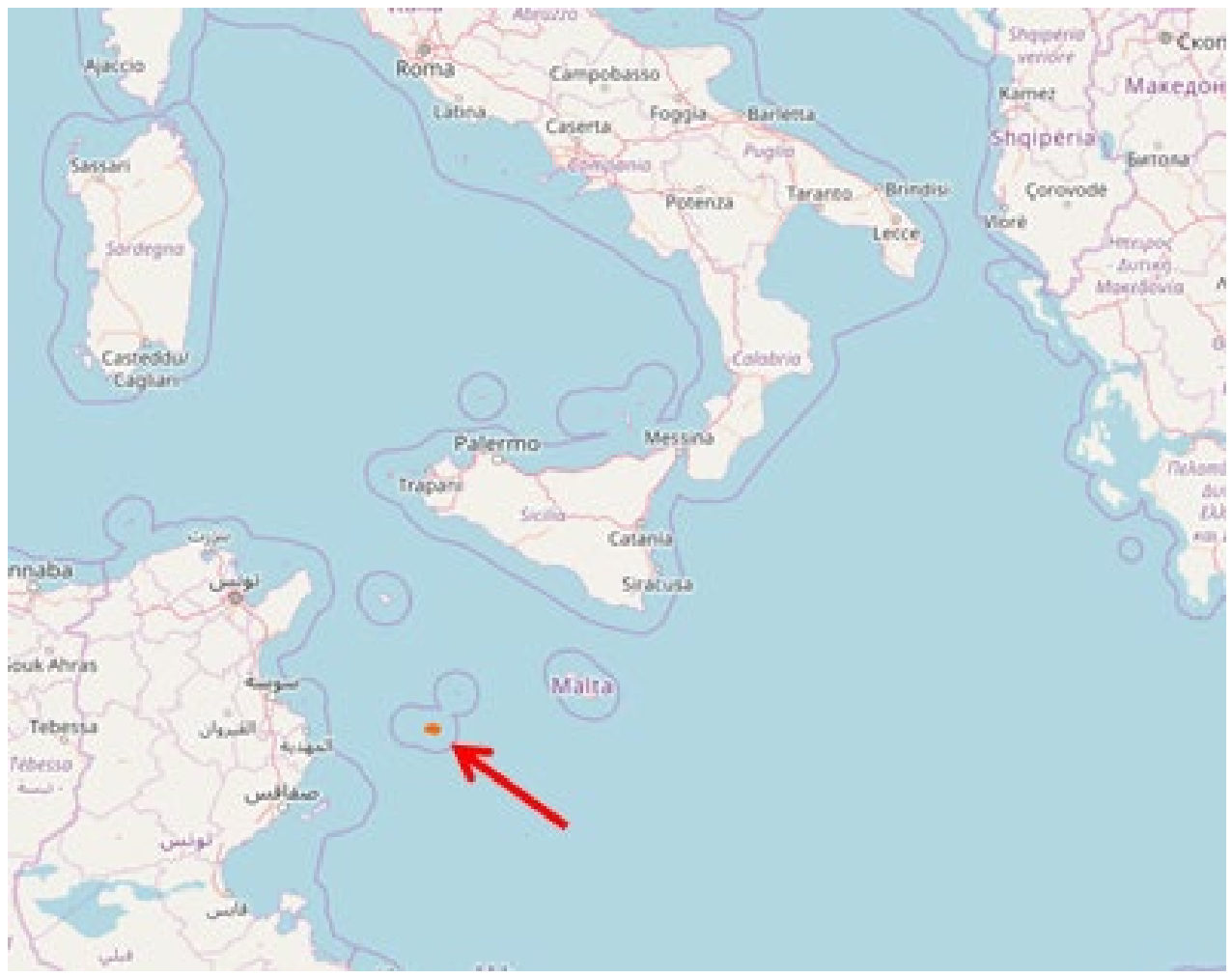

Fig. 2.

The SONET GNSS Reference Station Lampedusa in Southern Central Mediterranean Source: (OpenStreetMap, 2018)

We followed the methodology based on simulation of GPS positioning performance in real conditions using observed raw GPS pseudo-ranges fed into RTKLIB, an opensource software-defined GPS receiver, as depicted in Figs. 3 and 4, respectively. 


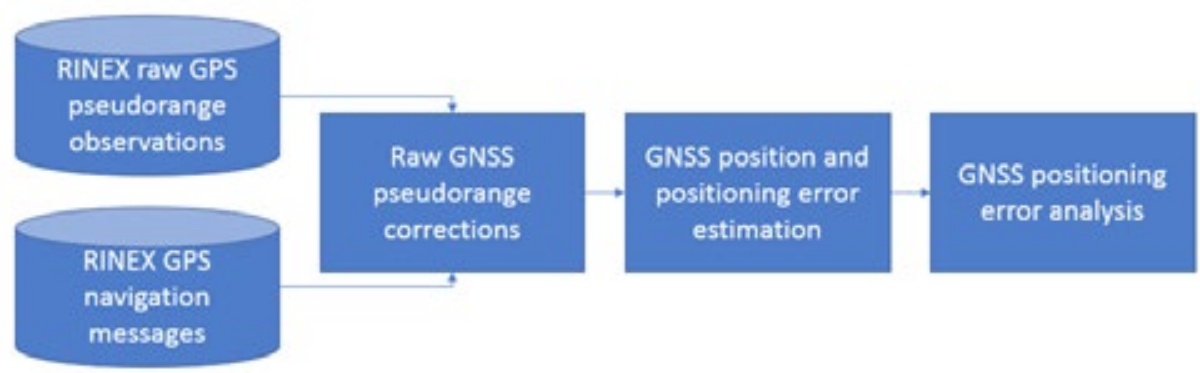

Fig. 3.

Methodology of Data Processing

Source: Authors

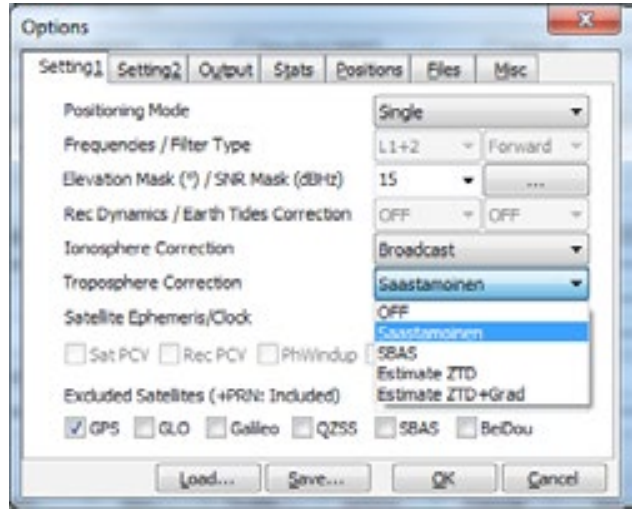

Fig. 4.

RTKLIB Configuration Menu with a Selection of Tropospheric Correction Modelling Alternatives Source: Authors and RTKLIB

The RTKLIB receiver was configured (Fig. 4) as a commercial-grade single-frequency GPS receiver, that utilised standard GPS satellite clock and ionospheric error correction models, whose parameters were extracted from the broadcast GPS navigation message. The time series of GPS-based position and positioning error estimates. The methodology was developed by two of the authors (MF and RF), and presented in more detail in (Filić et al., 2016).
The methodology deployed allowed us for flexibility in creation of two scenarios of GPS usage and deployment of different pseudo-range measurement corrections in navigation domain using the pseudoranges still retaining the original error effects produced in real environment. In Scenario A, the RTKLIB GPS SDR receiver (Takasu, 2013) was configured to process GPS pseudoranges without deployment of a GPS tropospheric correction model. 
Utilisation of the Saastamoinen GPS tropospheric error correction model based on the standard atmosphere yielded GPS position and positioning error estimates in Scenario B.

The RTKLIB (Takasu, 2013) post-processing procedure returns time series of GPS/GNSS position and positioning error estimates, throughout the day and with a $30 \mathrm{~s} \mathrm{lag}$. Time series of northing, easting and height GPS positioning errors were statistically analysed using bespoke software two of the authors (MF and RF) developed in the R opensource environment for statistical computing (R-project team, 2018).

\subsection{Study Results}

This section outlines the study results, as emerged from deployment of methodology presented in Section 2.3. The Saastamoinen model corrections were obtained using the embedded standard atmosphere model. This study encompassed the period between 13 November, 2017 and 16 November, 2018, thus assessing the conditions resulted from the passage of Numa medicane.

The post-processing procedure, outlined in Section 4, resulted in time series of northing and easting GPS positioning errors with scenarios of un-compensated and Saastamoinen-corrected GPS pseudoranges, respectively, that were used in position and positioning error estimation process (Filić et al., 2016), (Filić, 2017).

The rest of this section provides statistical analysis summaries of horizontal GPS positioning performance based on uncorrected (Table 1) and corrected (Table 2) observed GPS pseudoranges, as well as of residual GPS positioning errors (Table 3).

\section{Table 1}

Statistical Properties of GPS Positioning Errors, Un-Corrected for Tropospheric Delay

\begin{tabular}{|c|c|c|c|c|}
\hline & $\begin{array}{c}\text { 13 November } \\
\mathbf{2 0 1 7} \\
\text { (day 316) }\end{array}$ & $\begin{array}{c}\text { 14 November, } \\
\mathbf{2 0 1 7} \\
\text { (day 317) }\end{array}$ & $\begin{array}{c}\text { 15 November, } \\
\mathbf{2 0 1 7} \\
\text { (day 318) }\end{array}$ & $\begin{array}{c}\text { 16 November, } \\
\mathbf{2 0 1 7} \\
\text { (day 319) }\end{array}$ \\
\hline $\begin{array}{c}\text { Northing error }- \\
\text { mean }\end{array}$ & 4.006 & 4.001 & 4.027 & 4.006 \\
\hline $\begin{array}{c}\text { Northing error - } \\
\text { standard deviation }\end{array}$ & 1.063 & 1.064 & 1.095 & 1.063 \\
\hline Easting error - mean & 3.058 & 3.059 & 3.062 & 3.058 \\
\hline $\begin{array}{c}\text { Easting error - } \\
\text { standard deviation }\end{array}$ & 0.574 & 0.594 & 0.577 & 0.574 \\
\hline
\end{tabular}

Source: Authors 


\section{Table 2}

Statistical Properties of GPS Positioning Errors, Corrected For Tropospheric Delay According To

Saastamoinen

\begin{tabular}{|c|c|c|c|c|}
\hline & $\begin{array}{c}\text { 13 November } \\
\mathbf{2 0 1 7} \\
\text { (day 316) }\end{array}$ & $\begin{array}{c}\text { 14 November, } \\
\mathbf{2 0 1 7} \\
\text { (day 317) }\end{array}$ & $\begin{array}{c}\text { 15 November, } \\
\text { 2017 } \\
\text { (day 318) }\end{array}$ & $\begin{array}{c}\text { 16 November, } \\
\text { 2017 } \\
\text { (day 319) }\end{array}$ \\
\hline $\begin{array}{c}\text { Northing error }- \\
\text { mean }\end{array}$ & 2.873 & 2.868 & 2.896 & 2.873 \\
\hline $\begin{array}{c}\text { Northing error - } \\
\text { standard deviation }\end{array}$ & 0.735 & 0.734 & 0.767 & 0.735 \\
\hline Easting error - mean & 2.208 & 2.207 & 2.212 & 2.208 \\
\hline $\begin{array}{c}\text { Easting error }- \\
\text { standard deviation }\end{array}$ & 0.424 & 0.439 & 0.419 & 0.424 \\
\hline
\end{tabular}

Source: Authors

\section{Table 3}

Statistical Properties of GPS Positioning Error Residuals (Un-Corrected Position Estimates - Corrected Position Estimates)

\begin{tabular}{|c|c|c|c|c|}
\hline & $\begin{array}{c}\text { 13 November } \\
\mathbf{2 0 1 7} \\
\text { (day 316) }\end{array}$ & $\begin{array}{c}\text { 14 November, } \\
\mathbf{2 0 1 7} \\
\text { (day 317) }\end{array}$ & $\begin{array}{c}\text { 15 November, } \\
\mathbf{2 0 1 7} \\
\text { (day 318) }\end{array}$ & $\begin{array}{c}\text { 16 November, } \\
\text { 2017 } \\
\text { (day 319) }\end{array}$ \\
\hline $\begin{array}{c}\text { Northing error - } \\
\text { mean }\end{array}$ & 1.133 & 1.133 & 1.131 & 1.133 \\
\hline $\begin{array}{c}\text { Northing error - } \\
\text { standard deviation }\end{array}$ & 0.376 & 0.374 & 0.367 & 0.376 \\
\hline Easting error - mean & 0.850 & 0.852 & 0.850 & 0.850 \\
\hline $\begin{array}{c}\text { Easting error - } \\
\text { standard deviation }\end{array}$ & 0.205 & 0.202 & 0.205 & 0.205 \\
\hline
\end{tabular}

\section{Source: Authors}

Numa medicane hit the city of Lampedusa on 15 th November, 2017, consequently raising the GPS position error levels. Time series of northing and easting components

No tropo corrections

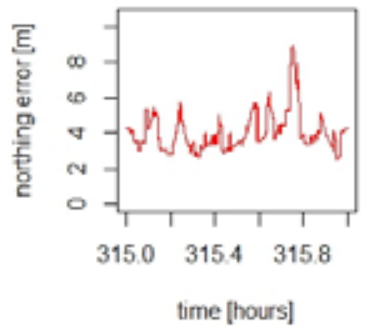

of GPS positioning error on 15th November, 2017, obtained with un-corrected GPS pseudorange observations, are presented in Fig. 5.

\section{Fig. 5.}

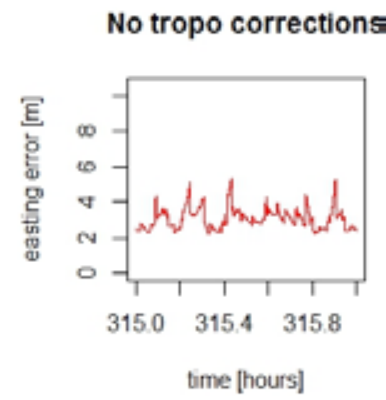

Time Series of Northing (Left) and Easting (Right) GPS Positioning Error Components, Derived From Un-Corrected GPS Pseudoranges, on $15^{\text {th }}$ November, 2017

Source: Authors 
Time series of northing and easting components of GPS positioning error on 15 th November, 2017, obtained with
Saastamoinen-corrected GPS pseudorange observations, are presented in Fig. 6.

\section{Saastamoinen corrections}

\section{Saastamoinen corrections}
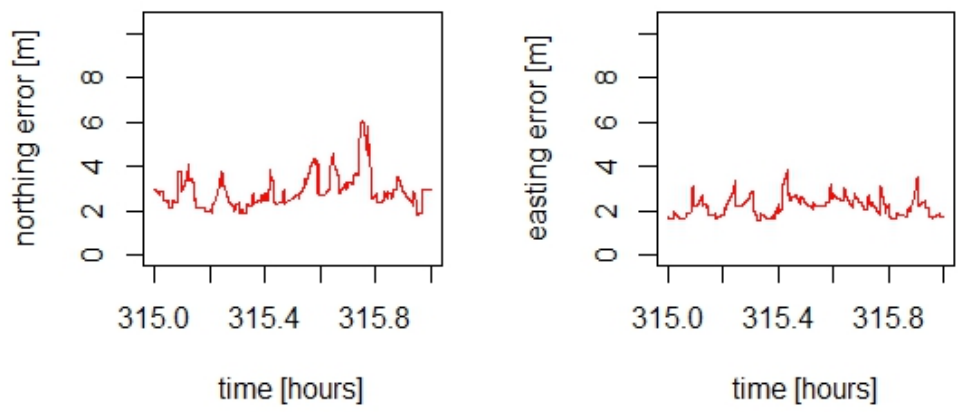

Fig. 6.

Time Series of Northing (Left) and Easting (Right) GPS Positioning Error Components, Derived from GPS Pseudoranges Corrected for Tropospheric Delay According to Saastamoinen, on $15^{\text {th }}$ November, 2017 Source: Authors

Essential residual analysis results are presented in Figs. 7 and 8, outlining time

\section{Northing error residuals}

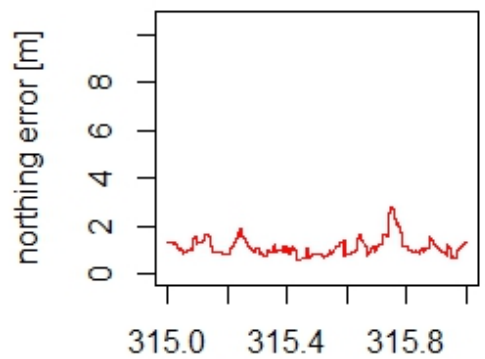

time [hours] series and histograms of components residuals, respectively.

\section{Easting error residuals}

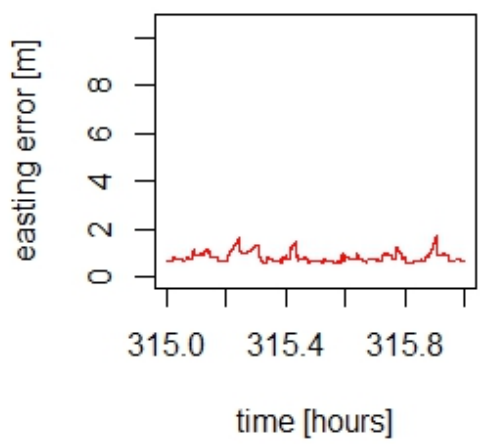

Fig. 7.

Time Series of Northing (Left) and Easting (Right) GPS Positioning Error Components Residuals, on $15^{\text {th }}$ November, 2017

Source: Authors 

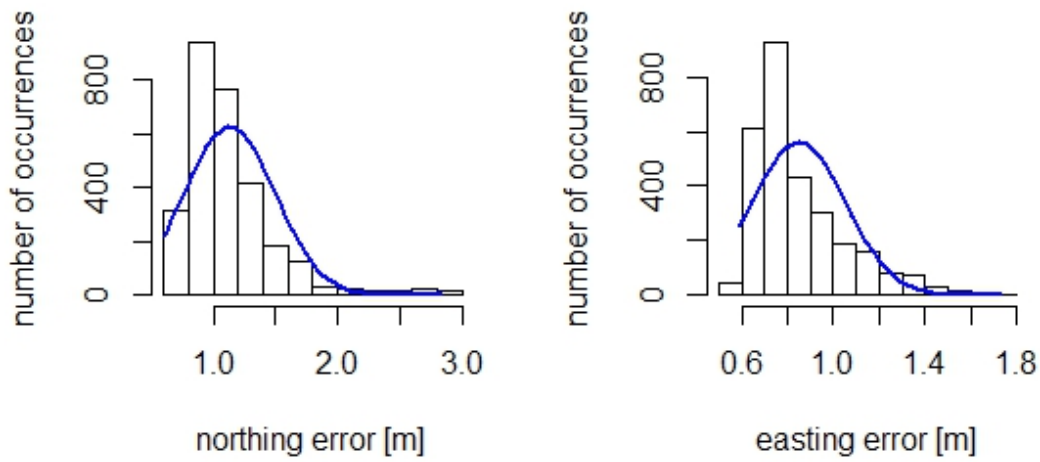

Fig. 8.

Histograms of Northing (Left) and Easting (Right) GPS Positioning Error Components Residuals on $15^{\text {th }}$ November, 2017

Source: Authors

\section{Discussion and Conclusion}

Studies of GNSS positioning performance in adverse and seriously disturbed positioning environments reveal the information about the nature and causes of GNSS positioning performance degradation. The insight achieved from those studies may steer development of resilient GNSS, either in general or for specific classes of GNSS applications. Here we presented the results of a study of single-frequency commercialgrade GPS positioning performance in the recent (15th November, 2017) case of rapidly developing tropospheric storm (a Mediterranean cyclone, or a medicane), using post-processing simulation approach based on experimentally collected GPS pseudoranges at the stationary reference site in the southern Mediterranean. The analysis of GPS pseudorange-based position error estimates identified medicane-caused GPS tropospheric error impact correlated with Numa medicane passage over the GNSS reference station Lampedusa, Italy.
Statistical analysis of components of GPS positioning error time series revealed pronounced impact on northing component of GPS positioning error. The northing component rose during the passage of Numa medicane for approximately $0.5 \%$ for uncompensated, and for approximately $1 \%$ for Saastamoinen-corrected GPS pseudoranges, respectively, compared with the conditions preceding Numa medicane. The easting GPS positioning error was far less affected, with respective values of un-compensated and Saastamoinen-corrected GPS pseudoranges causing the GPS positioning error due to tropospheric delay increasing by less than $0.1 \%$ compared with the calm weather conditions preceding Numa medicane. Residuals did not follow normal (Gaussian) distribution.

In absolute terms, the Numa medicane raised the GPS positioning error due to increased tropospheric delay at the centimetre level. Contribution of the medicane-caused component to the over-all GPS positioning error budget is measurable, but insignificant 
compared with the other contributors. Our study showed that in consideration of maritime navigation GPS applications, most of them will remain un-affected even by severe weather development, such as a medicane. Still, the new GNSS applications, including autonomous vessels, that require high-precision will require advanced methods for tropospheric delay mitigation. The quest will become more challenging for case scenarios involving the open seas operation, where the infrastructure for additional information support to navigation remains scarce. Utilisation of real-time experimental measurements of weather parameters to feed the Saastamoinen model instead of utilisation of the standard atmosphere model emerges as a potential solution.

Lack of systematically collected meteorological data prevented a more thorough analysis of Saastamoinen correction based on actual observations, rather than the utilisation of the standard atmosphere model. RINEX m data sets, comprising meteorological data observations taken in 30-second intervals throughout the day, are optionally provided by some GNSS reference sites, but not for the stations in the region affected by Numa medicane. The solution for the problem, and an assessment of observation-supported Saastamoinen tropospheric error corrections, remain as the subject for further research.

In summary, we presented a case of severe weather development in maritime domain and examined it from the perspective of potential effects on GNSS/GPS positioning performance. We found a measurable contribution to the over-all GPS positioning error, that can be neglected for majority of maritime navigation applications but remains as a concern for the high-precision and emergency navigation applications at sea. Further research will focus on development of bespoke mitigation methods for categories of GNSS-based maritime navigation applications.

\section{References}

Cavicchia, L.; von Storch, H.; Gualdi, S. 2014. Mediterranean Tropical-Like Cyclones in Present and Future Climate, Journal of Climate 27(19): 7493-7501.

Cove, K. 2005. Improvements in GPS tropospheric delay estimation with numerical weather prediction (Technical Report TR230). Department of Geodesy and Geomatics Engineering. University of New Brunswick. Canada. $114 \mathrm{p}$.

Filić, M. 2017. An analysis of pseudorange-based methods for position estimation in a software-defined satellite navigation radio receiver ( $\mathrm{MSc}$ thesis, in Croatian). Department for Mathematics, Faculty of Science, University of Zagreb. Croatia. 94 p.

Filić, M.; Filjar, R.; Ruotsalainen, L. 2016. An SDRbased Study of Multi-GNSS Positioning Performance During Fast-developing Space Weather Storm, TransNav: International Journal on Marine Navigation and Safety of Sea Transportation 10(3): 395-400.

Free University of Berlin. 2017. Europe Weather Analysis on 2017-11-16. Available from internet: <https://bit. ly/2GZnY8W>.

Hohenkerk, C.Y.; Sinclair, A.T. 1985. The Computation of Angular Atmospheric Refraction at Large Zenith Angles. NAO Technical Note No. 63. The Royal Greenwich Observatory, HM Nautical Almanac Office, United Kingdom Hydrographic Office. UK. 14p.

Katsougiannopoulos, S.; Pikridas, C.; Rossikopoulos, D.; Ifadis, I.; Fotiou, A. 2006. Tropospheric refraction estimation using various models, radiosonde measurements and permanent GPS data. In Proceedings of the XXIII FIG Congress, $15 \mathrm{p}$. 
Markežić, I.; Filjar, R.; Juričić, I. 2002. Time distribution of the GPS signal tropospheric delay during passage of the warm front. In Proceedings of the $2^{\text {nd }}$ Congress Transport Traffic and Logistics, 345-348.

NASA. 2017. MODIS Aqua image of the Central Mediterranean with Medicane NUMA. Available from internet: <https://worldview.earthdata.nasa.gov>.

Nauenberg, M. 2016. Atmospheric Refraction Based on Atmospheric Pressure and Temperature Data. arxiv. org, No. 1609.08921. Available from internet: <http:// bit.ly/2ClTEDb>.

OpenStreetMap. 2018. Available from internet: <https://www.openstreetmap.org>.

Romero, R.; Emanuel, K. 2017. Climate Change and Hurricane-Like Extratropical Cyclones: Projections for North Atlantic Polar Lows and Medicane Based on CMIP5 Models, Journal of Climate 30(1): 279-299.

Royal Netherlands Meteorological Institute. 2018. European Climate Assessment and Dataset. Available from internet: <https://www.ecad.eu>.

R-project team. 2018. The R project for Statistical Computing (software, documentation, and books). Available from internet: <https://www.r-project.org $>$.
Shrestha, S.M. 2003. Investigations into the Estimation of Tropospheric Delay and Wet Refractivity Using GPS Measurements (Technical Report No. 20180). Department of Geomatics Engineering, University of Calgary. Canada.

Sweezy, W.B.; Bean, B.R. 1962. Correction of Atmospheric Refraction Errors in Radio Height Finding, Journal of Research of the National Bureau of Standards - D. Radio Propagation 67(2): 139-151.

Takasu, T. 2013. RTKLIB: An Open Source Program Package for GNSS Positioning - Software and documentation. Available from internet: <http://www. rtklib.com>.

Thomas, M.; Norton, J.; Jones, A.; Hopper, A.; Ward, N.; Cannon, P.; Ackroyd, N.; Cruddace, P.; Unwin, M. 2011. Global navigation space systems: reliance and vulnerabilities. The Royal Academy of Engineering, London. UK. 48 p. Tous, M.; Romero, R. 2013. Meteorological environments associated with medicane development, International Journal of Climatology 33(1): 1-14.

UN OOSA. 2012. Current and Planned Global and Regional Navigation Satellite Systems and Satellite-based Augmentation Systems. UN Office of Outer Space Affairs (OOSA). Austria. 70 p. 